\begin{tabular}{ll} 
Bentham open & The Open Dentistry Journal \\
CrossMark & Content list available at: www.benthamopen.com/TODENTJ/ \\
\hline
\end{tabular}

RESEARCH ARTICLE

\title{
Bond to Zirconia Ceramic: Evaluation of Different Primers and a Universal Adhesive
}

Diego Fabris Ferreira da Silva ${ }^{1}$, Raquel de Oliveira Lopes ${ }^{1}$, Niélli Caetano de Souza ${ }^{1}$, Maurem Leitão Marcondes ${ }^{1}$, Patrícia Danesi ${ }^{1}$ and Ana Maria Spohr ${ }^{2, *}$

${ }^{I}$ Department of Restorative Dentistry, Pontifical Catholic University of Rio Grande do Sul, Porto Alegre, Rio Grande do Sul, Brazil

${ }^{2}$ Department of Dental Materials, Pontifical Catholic University of Rio Grande do Sul, Porto Alegre, Rio Grande do Sul, Brazil

Received: May 26, 2018

Revised: September 26, 2018

Accepted: October 7, 2018

\section{Abstract:}

Objective:

The aim of the study was to evaluate the effect of a universal adhesive and different primers on the bond strength to zirconia ceramic.

\section{Materials and Methods:}

Seventy-five zirconia ceramic samples were obtained and divided into five groups ( $\mathrm{n}=15$ ): G1-Scothbond Universal (SBU); G2 silane + SBU; G3 - Signum Zirconia Bond; G4 - Z-Prime Plus; G5 - MZ Primer. A cone of composite resin was built. The specimens were stored in $100 \%$ relative humidity with distilled water at $37^{\circ} \mathrm{C}$ for $48 \mathrm{~h}$ and then submitted to a tensile bond strength test in a universal testing machine at a crosshead speed of $0.5 \mathrm{~mm} / \mathrm{min}$. The type of failure that occurred during the de-bonding procedure was analyzed.

\section{Results:}

The mean results of the bond strength test (MPa) followed by the same letter represent no statistical difference by ANOVA and Tukey's post-hoc test $(p<0.05)$ : G2=27.55 $( \pm 6.99), \mathrm{G} 4=23.71^{\mathrm{a}}( \pm 5.65), \mathrm{G} 1=22.64^{\mathrm{a}}( \pm 5.67), \mathrm{G} 5=13.64^{\mathrm{b}}( \pm 5.49), \mathrm{G} 3=7.54^{\mathrm{c}}( \pm 4.75)$. G2 and G4 exhibited predominantly cohesive failure in the composite resin cone. G1 and G5 had predominantly mixed failures, and G3 exhibited only adhesive failures.

\section{Conclusion:}

The SBU and Z-Prime Plus provided higher bond strength to zirconia ceramic.

Keywords: Adhesives, Bond, Primers, Zirconia, Adhesion, Ceramic.

\section{INTRODUCTION}

For indirect restorations, different luting techniques can be employed, and the literature has shown that the use of adhesive techniques provides an increase in the fracture resistance of teeth $[1,2]$. Traditionally, the adhesive technique is the combination of an adhesive system with resin cement.

The process of bonding silica-based ceramics to resinous materials has been well established. One of the most effective treatment is hydrofluoric acid etching associated with silane application [3,4]. Both have the ability to

\footnotetext{
* Address Correspondence to this author at the Department of Dental Materials, Pontifical Catholic University of Rio Grande do Sul, Avenida Ipiranga, 6681, 90616-900 Porto Alegre, RS, Brazil; Tel: +55-51-3320.3538; E-mail: ana.spohr@pucrs.br
} 
increase the wettability of the resinous material on the surface of the ceramic $[5,6]$. The micromechanical bond is achieved by the penetration of the adhesive on the surface irregularities caused by acid etching. The chemical bond is achieved by silane, which promotes the bond between Si-containing surfaces and organic polymeric materials [7, 8].

Regarding the zirconia ceramic, neither etching with hydrofluoric acid [9, 10] nor silane application, such as 3Methacryloyloxypropyltrimethoxysilane (MPS) are effective [11, 12], as this ceramic consists of Yttrium-stabilized Tetragonal Zirconia Polycrystals (Y-TZP) and has no silica in its composition [13]. Thus, various surface treatments have been proposed for zirconia ceramic, such as aluminum oxide sandblasting [9, 14], tribochemical silica coating [15, 16], selective infiltration-etching technique [17], and $\mathrm{CO}_{2}$ laser irradiation [18]. Primers containing functional monomers have also been developed which promote bonding to metal oxides such as zirconia [19 - 21]. The association of methods has shown better bond strength results than their separate use. Thus, aluminum oxide sandblasting followed by the application of zirconia primers, as well as tribochemical silica coating followed by silanization, are the two most popular methods for bonding to zirconia ceramic [19, 22, 23]. However, the most suitable clinical protocol is still under discussion for zirconia ceramic [20].

A new category of adhesive systems, known as universal adhesives, was launched with the aim of technical simplification. These adhesive systems may be used as self-etch adhesives, etch-and-rinse adhesives, or as self-etch adhesives on dentin and etch-and-rinse adhesives on enamel (selective enamel etching). In addition, these adhesives can be applied on the surface of different restorative materials [24]. The universal adhesives contain carboxylate and/or phosphate monomers, such as 10-MDP, and some of them contain silane [24]. A representative of this category is Scotchbond Universal (SBU), which proclaims to contain a silane besides 10-MDP monomers, which bond chemically to metal ions [25].

The possibility of using a universal adhesive on zirconia ceramic could eliminate the use of specific primers for zirconia. Furthermore, it is important that an adhesive has a similar or better capacity in comparison with primers for zirconia. Among the primers for zirconia ceramic, different products are available. Studies have been developed to compare the bond strength of universal adhesives and primers for zirconia [22, 26 - 28]. However, more studies regarding the bond capacity of SBU to zirconia ceramic are needed to validate the technical simplification declared by the manufacturer, especially with a tension methodology that is different from the testing applied by the other studies.

Therefore, the present study has the aim to evaluate the effect of universal adhesive and different primers on the bond strength to zirconia ceramic. This study was conducted with the hypothesis that there is no difference in bond strength to zirconia ceramic when universal adhesive and different primers are used.

\section{MATERIALS AND METHODS}

Seventy-five samples of zirconia ceramic (Talmax, Curitiba, PR, Brazil) were made (Table 1). The samples had a thickness of $3 \mathrm{~mm}$, with a smaller base $6 \mathrm{~mm}$ in diameter and a larger base $8 \mathrm{~mm}$ in diameter (Fig. 1a). These samples were prepared in a dental laboratory.

Table 1. Materials and their composition and manufacturer.

\begin{tabular}{|c|c|c|}
\hline Material & Composition & Manufacturer \\
\hline $\begin{array}{l}\text { Zirconia ceramic } \\
\text { (Talmax) }\end{array}$ & $\begin{array}{c}\mathrm{ZrO}_{2} \text { (main component), } \mathrm{Y}_{2} \mathrm{O}_{3}(12 \%), \mathrm{Al}_{2} \mathrm{O}_{3}(1 \%), \mathrm{SiO}_{2}(0,02 \%), \mathrm{Fe}_{2} \mathrm{O}_{3}(0,02 \%), \mathrm{Na}_{2} \mathrm{O} \\
(0,02 \%), \mathrm{HfO}_{2}(12 \%)\end{array}$ & Talmax, Curitiba, PR, Brazil \\
\hline $\begin{array}{c}\text { Scotchbond Universal } \\
\text { (adhesive system) } \\
\text { (SBU) }\end{array}$ & $\begin{array}{l}\text { Organophosphate monomer (10-MDP), dimethacrylate resins (Bis-GMA, etc.), HEMA, } \\
\text { Vitrebond copolymer, filler, ethanol, water, initiators, silane }\end{array}$ & 3M/ESPE, St. Paul, MN, USA \\
\hline $\begin{array}{l}\text { RelyX Ceramic Primer } \\
\text { (silane) }\end{array}$ & $\begin{array}{l}\text { 3-methacryloxypropyltrimethoxysilane } \\
\text { (MPS), ethyl alcohol, water }\end{array}$ & 3M/ESPE, St. Paul, MN, USA \\
\hline $\begin{array}{l}\text { Signum Zirconia } \\
\text { Bond }\end{array}$ & $\begin{array}{c}\text { Zirconia Bond I (part I): Acetone, 10-MDP, acetic acid } \\
\text { Zirconia Bond II (part II): MMA, Diphenyl (2,4,6-trimethylbenzoyl) phosphinoxide }\end{array}$ & $\begin{array}{l}\text { Heraeus Kulzer, Hanau, } \\
\text { Germany }\end{array}$ \\
\hline Z-Prime Plus & Organophosphate monomer (10-MDP), carboxylic acid monomer, other monomers & Bisco, Schaumburg, IL, USA \\
\hline MZ Primer & PMDM, HEMA-p, methacrylate acid, benzoyl peroxide, acetone & Angelus, Londrina, PR, Brazil \\
\hline
\end{tabular}

HEMA: 2-Hydroxyethyl methacrylate; Bis-GMA: Bisphenol-A glycidyl methacrylate; 10-MDP: 10-Methacryloyloxydecyl Dihydrogen Phosphate; PMDM: Pyromellitic dimethacrylate. 

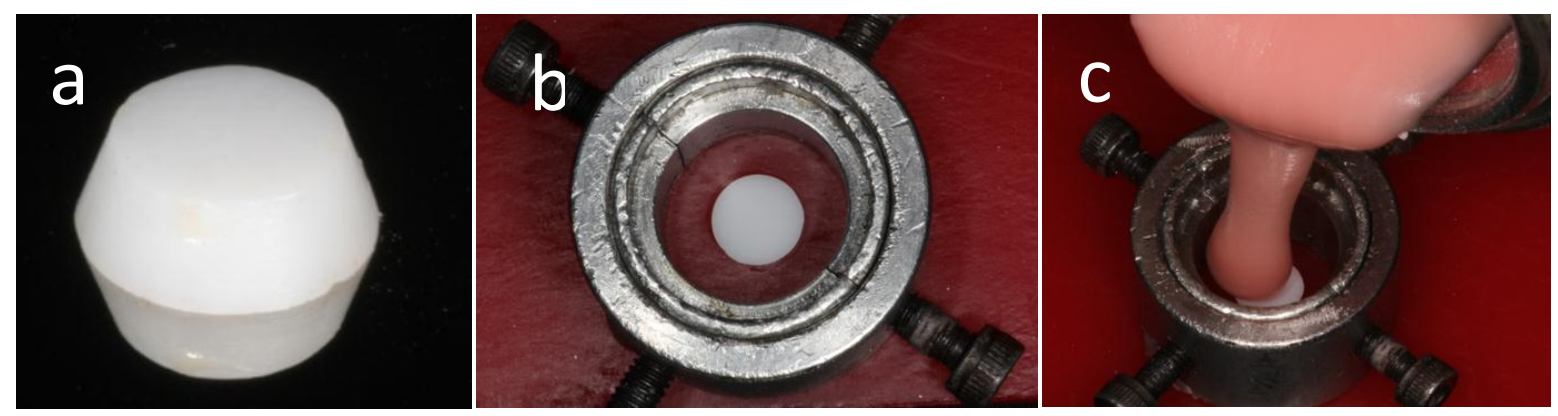

Fig. (1). a) Zirconia sample; b) metal matrix positioned on the wax and the sample centralized in the matrix; c) the matrix filled with self-cured acrylic resin.

The smaller diameter of the samples was fixed to a utility wax plaque. A metal matrix was positioned on the wax and the sample was kept centralized in the matrix (Fig. 1b). Then, the matrix was filled with self-cured acrylic resin (Jet Classico, São Paulo, SP, Brazil) (Fig. 1c). In the sequence, the surface of the samples was polished with 600 and 1200 grit silicon carbide abrasive papers in a polishing machine (DPU-10, Panambra, São Paulo, SP, Brazil) under water. The surface of the zirconia ceramic samples was sandblasted with $50 \mu \mathrm{m}$ aluminum oxide for $5 \mathrm{~s}$ (Fig. 2a), followed by rinsing with air and water spray for $30 \mathrm{~s}$. The samples were cleaned ultrasonically in isopropyl alcohol for $4 \mathrm{~min}$ and dried with air. The luting materials used are shown in Table 1. The zirconia samples were divided into five groups, and they underwent the luting procedures described in Table 2.
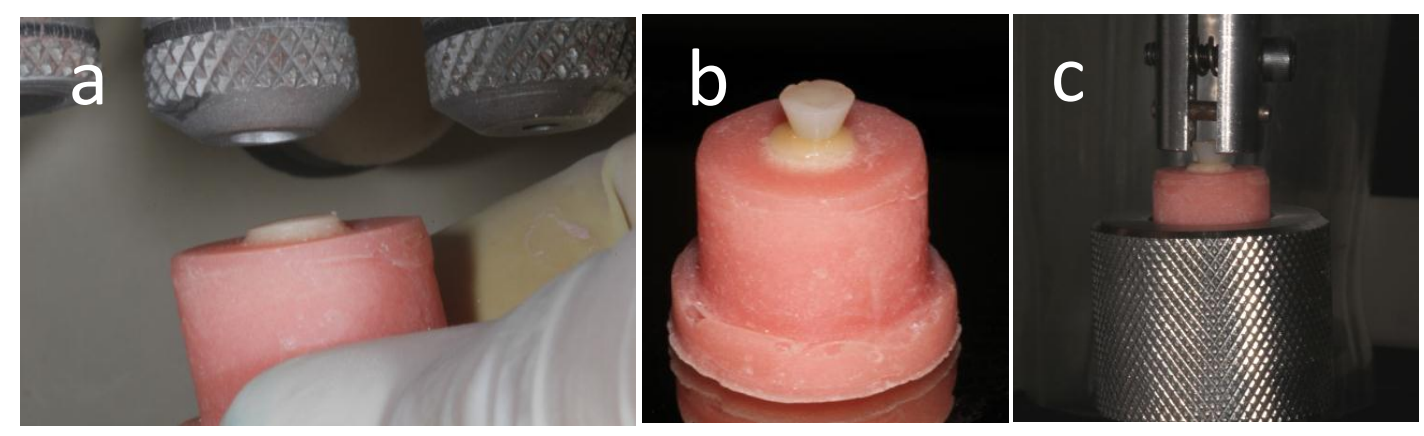

Fig. (2). a) sandblasting of the zirconia sample; b) specimen with the inverted cone of composite resin; c) specimen positioned for the tensile bond test.

Table 2. Luting procedures in the zirconia ceramic samples.

\begin{tabular}{|c|c|}
\hline Groups & Luting procedures \\
\hline Group $1-$ SBU & $\begin{array}{l}\text { A thin layer of the adhesive was applied, gently air-dried for } 5 \mathrm{~s} \text { and light-cured for } 10 \mathrm{~s} \text { with the light unit LED Radii } \\
\text { Cal. }\end{array}$ \\
\hline Group 2 - Silane + SBU & $\begin{array}{c}\text { A layer of the silane RelyX Ceramic Primer was applied and gently air-dried for } 5 \mathrm{~s} \text {. The adhesive SBU was applied } \\
\text { as described for group } 1 .\end{array}$ \\
\hline $\begin{array}{l}\text { Group } 3 \text { - Signum Zirconia } \\
\text { Bond (SZ) }\end{array}$ & $\begin{array}{c}\text { A layer of the Signum Zirconia Bond part I was applied and gently air-dried for } 5 \mathrm{~s} \text {. Then, a layer of Signum Zirconia } \\
\text { Bond part II was applied and light-cured for } 40 \mathrm{~s} \text { with the light unit LED Radii Cal. }\end{array}$ \\
\hline Group 4 - Z-Prime Plus (ZP) & $\begin{array}{l}\text { A layer of Z-Prime Plus was applied, gently air-dried for } 5 \mathrm{~s} \text {, and light-cured for } 40 \mathrm{~s} \text { with the light unit LED Radii } \\
\text { Cal. }\end{array}$ \\
\hline Group 5 - MZ Primer (MZ) & f MZ Primer was applied, gently air-dried for $5 \mathrm{~s}$, and light-cured for $40 \mathrm{~s}$ with the light unit LED Radii Cal. \\
\hline
\end{tabular}

SBU - Scotchbond Universal.

A metallic split cylinder, $4 \mathrm{~mm}$ high with a 3-mm-diameter orifice at the bottom and 5-mm-diameter orifice at the top, was placed against the adhesive or primer applied on the surface of the samples. The composite resin Empress Direct was inserted in the interior of the orifice in two increments to form an inverted cone of composite resin (Fig. 2b), which provided a grip for the clutch used in the tensile bond test (Fig. 2c). Each increment was light-cured for $20 \mathrm{~s}$ with the curing unit Radii Cal (SDI, Bayswater, Vic, Australia) with a light intensity of $1,000 \mathrm{~mW} / \mathrm{cm}^{2}$. The light intensity was controlled by a radiometer (LED Curing Radiometer, Demetron, USA). 
The specimens were stored in $100 \%$ relative humidity with distilled water at $37^{\circ} \mathrm{C}$ for $48 \mathrm{~h}$. The specimens in each group $(\mathrm{n}=15)$ were submitted to tensile bond strength tests in a universal testing machine (EMIC DL-2000, São José dos Pinhais, PR, Brazil) at a crosshead speed of $0.5 \mathrm{~mm} / \mathrm{min}$. The tensile bond strength values in MPa were calculated from the peak load at failure divided by the specimen surface area.

After the tensile bond strength tests, the fractured surfaces of the specimens were visually examined with a stereomicroscope (Olympus Corp., Tokyo, Japan) at x20 to classify the type of failure that occurred during the debonding procedure. The failures were classified as follows: a) adhesive: rupture in the interface between the ceramic and the adhesive or primer; b) cohesive: cohesive failure in the ceramic or in the composite resin cone; c) mixed (adhesive and cohesive failure).

Tensile bond strength values were submitted to the Shapiro-Wilk normality test. As there was normality in the values of bond strength, the data were analyzed by ANOVA and Tukey's test. $P<0.05$ was considered significant.

\section{RESULTS}

Group 2 (27.55 MPa) obtained the highest mean bond strength, which was not significantly different from group 4 (23.71 MPa) and group $1(22.64 \mathrm{MPa})$. An intermediate value was obtained for group 5 (13.64 MPa), differing significantly from the other groups $(p<0.05)$. Group $3(7.54 \mathrm{MPa})$ had the lowest mean, differing significantly from the other groups $(p<0.05)$. Groups 2 and 4 exhibited predominantly cohesive failure in the composite resin cone. Groups 1 and 5 had predominantly mixed failures (adhesive and cohesive failure in the composite resin cone), and group 3 exhibited only adhesive failures (Table 3). Fig. (3) shows images of adhesive failure, cohesive failure and mixed failure that occurred in the specimens.

Table 3. Mean tensile bond strength (MPa), standard deviation and failure types in the zirconia ceramic groups.

\begin{tabular}{|c|c|c|}
\hline Groups & Bond Strength Means (MPa) and Standard Deviations & Failure Types \\
\hline Group $2-$ Silane + Scotchbond Universal & $27.55^{\mathrm{a}}( \pm 6.99)$ & $\begin{array}{c}-13 \text { cohesive in composite resin cone } \\
-2 \text { mixed* }\end{array}$ \\
\hline Group 4 - Z Prime Plus & $23.71^{\text {a }}( \pm 5.65)$ & $\begin{array}{c}\text { - } 11 \text { cohesive in composite resin cone } \\
-4 \text { mixed* }\end{array}$ \\
\hline Group $1-$ Scotchbond Universal & $22.64^{\mathrm{a}}( \pm 5.67)$ & $\begin{array}{c}-6 \text { cohesive in composite resin cone } \\
-9 \text { mixed }\end{array}$ \\
\hline Group 5-MZ Primer & $13.64^{\mathrm{b}}( \pm 5.49)$ & $\begin{array}{c}-12 \text { mixed* } \\
-2 \text { cohesive in composite resin cone } \\
-1 \text { adhesive }\end{array}$ \\
\hline Group 3 - Signum Zirconia Bond & $7.54^{\mathrm{c}}( \pm 4.75)$ & - 15 adhesive \\
\hline
\end{tabular}

Medians followed by different letters in the columns differ significantly according to Tukey's test at a significance level of $5 \%$.

*Mixed failure: adhesive and cohesive in the composite resin cone.
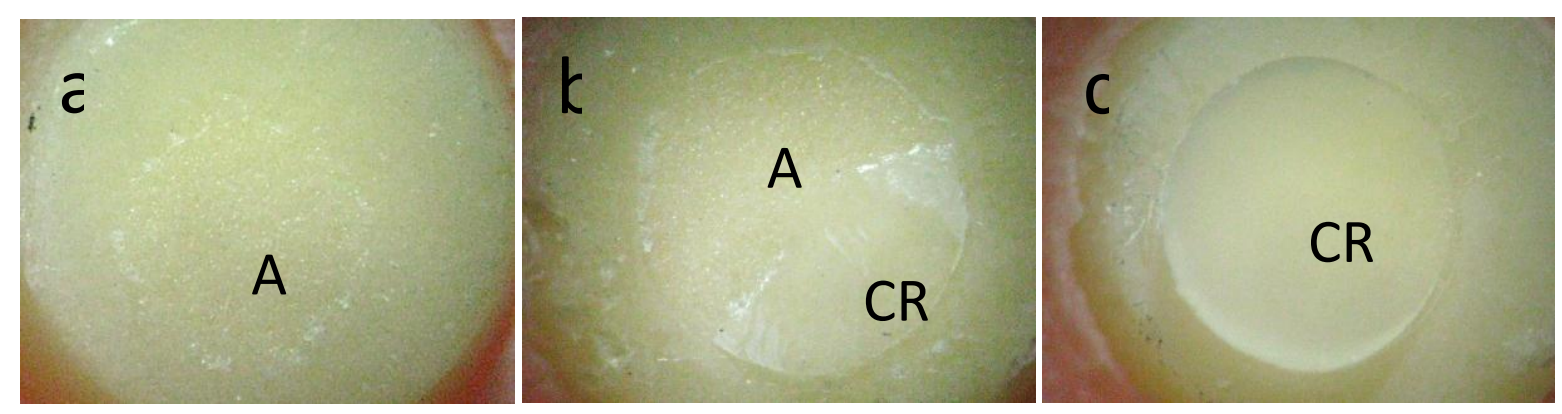

Fig. (3). Stereomicroscope images of the failures occurred in the composite resin specimens: a) Adhesive failure (x10): A - adhesive; b) Mixed failure (x20): A - adhesive; $\mathrm{CR}$ - cohesive in composite resin cone; c) Cohesive failure (x20): CR - cohesive in composite resin cone.

\section{DISCUSSION}

The hypothesis was rejected because the study showed differences in the bond strength to zirconia ceramic with the application of zirconia primers and the SBU. Only the Z-Prime Plus primer did not differ significantly from the SBU alone or associated with silane. 
The SBU has Bis-GMA and HEMA in its composition, as well as a 10-MDP monomer, polyalkenoic acid copolymer, dimethacrylate resin, filler, ethanol, water, initiators, and silane. The 10-MDP monomer has a great affinity to metal oxides such as Zirconium Dioxide $\left(\mathrm{ZrO}_{2}\right)[22,26,29]$. This monomer has effective bonding between the MDP acidic groups (phosphoric acid) and the oxide layer of the zirconia, improving the bond strength between zirconia ceramic and resinous substrate [30,31]. Therefore, the presence of the 10-MDP monomer favored the bond between SBU and zirconia ceramic. The results for the SBU corroborate those of another study [22, 28].

The present study also evaluated the application of silane before the SBU. Silane coupling agents are usually monomeric species, such as MPS (3-Methacryloxypropyltrimethoxysilane), in which silicon is linked to reactive organic radicals and hydrolysable ester groups. The reactive organic groups become chemically bonded to the resin molecules, such as Bis-GMA and HEMA monomers present in the adhesives, resin cements. Hydrolysable monovalent groups bond chemically to silicon contained in the glassy matrix of the ceramics [32]. Zirconia ceramic contains zirconium oxide and not silicon, and the chemical bonding does not occur. So, the application of silane before the SBU did not significantly influence the bond strength values for the zirconia ceramic. However, although there was no significant difference between group 1 and group 2, the bond strength value was higher when the silane was applied prior the SBU, and a greater degree of cohesive failure in composite resin cone occurred. This may be related to the physical effect of silane, which improves the wettability of the ceramic surface, allowing greater contact between the adhesive and the ceramic [5]. This surface wettability promoted by the silane must have contributed to the bond strength values, regardless its incorporation into the adhesive or separate application.

The Z-Prime Plus is a primer based on 10-MDP and carboxylic acid. A study using secondary ion mass spectrometry indicated the formation of a chemical bond (Zr-O-P) between zirconia ceramic and 10-MDP-containing zirconia primer [29]. This affinity is explained by the capacity of the phosphate group to react with zirconium, forming zirconium phosphate, where each phosphate group is bound to three zirconium atoms (tridentate bridging mode) or to one zirconia atom (tridentate chelating mode), conferring a thermally and hydrolytically stable interface [21]. The other monomers contained in the primer, such as the carboxylic acid monomer, cooperate in the bond process [33]. The results obtained with Z-Prime Plus are consistent with the findings in the study of Seabra et al. [27], which found no significant difference in the bond strength to the zirconia ceramic treated with Z-Prime Plus and the universal adhesives All Bond Universal and SBU. Pereira et al. [26] also found no difference in bond strength for the groups wherein the zirconia was sandblasted with aluminum oxide and treated with Z-Prime Plus and the SBU. However, in the study of Lopes et al. [28], Z-Prime Plus obtained significantly lower bond strength than SBU. The differences in results between studies may be related to many factors such as the testing method applied to evaluate the bond strength as well as the operator and manipulation of the materials.

Although there was no significant difference between groups 1, 2 and 4, the failures were predominantly cohesive in the composite resin cone in groups 2 and 4, and there were more mixed failures in group 1 with a decrease in the bond strength values. Mixed failure is characterized by the sum of the adhesive failure (between the resinous material and the ceramic substrate) and the cohesive failure in the composite resin cone. Therefore, the bond capacity of the materials used in groups 2 and 4 exceeded the cohesive strength of the composite resin cone. Thus, the methodology employed in the present study had the limitation of being able to evaluate the bonding interface when the bond strength values were high, preventing the definition of which treatment is the most effective, i.e., the SBU adhesive system associated with the silane or the Z-Prime Plus Primer.

MZ Primer had an intermediate bond strength value. Z-Prime Plus, Signum Zirconia Bond and SBU have the 10MDP monomer as the main component, and MZ Primer has a dicarboxyl monomer (PMDM). Pilo et al., [21], evaluated the changes in the surface chemistry of zirconia ceramic induced by two primers for zirconia, one with PMDM (Danville Z Bond) and the other with 10-MDP (Z-Prime Plus). While the primer with 10-MDP formed an amorphous thick film of zirconium phosphate salt, the primer with PMDM formed a thinner film of zirconium carboxylate salt, which is more sensitive to hydrolysis. According to the authors, the differences in the film-forming properties and water solubility between the carboxylate and phosphate salts may affect the strength and the durability of adhesive resin interfaces with zirconia ceramic. It is believed that this explains the lower values of bond strength obtained with $\mathrm{MZ}$ Primer when compared to Z-Prime Plus and SBU.

Signum Zirconia Bond had the lowest bond strength mean. Although this primer has 10-MDP in its composition, this material did not have the same bonding ability compared with the SBU and Z-Prime Plus. This finding does not corroborate with other studies [28, 34]. Maeda et al., [34], found higher bond strength to zirconia using the Signum Zirconia Bond primer in association with the resin cements Panavia F, NX3, seT and Multilink compared with the Z- 
Prime Plus. According to the authors, in addition to the effect of 10-MDP, the MMA found in Signum Zirconia Bond sets primary links with methacrylates present in the resin cement, resulting in increased bond strength. In addition, this study showed that the combination of primers for zirconia and resin cements significantly affected the bond strength to zirconia ceramics [34]. Lopes et al. [28], also tested Signum Zirconia Bond primer in association with a resin cement. In the present study, a composite resin was used instead of a resin cement to bond to the primer. Thus, the hypothesis that the composite resin does not favor a bond to the Signum Zirconia Bond as much as that obtained with a resin cement, such as Panavia F [34] or Duo-Link [28], cannot be ruled out.

High bond strength is important for clinical success in restorations luted adhesively. The good results of universal adhesives can represent a significant improvement in luting zirconia ceramic restorations. Thus, clinicians can use the same adhesive and the same protocol on the tooth and the surface of the restorations. Regarding silane, it is not yet clear whether its effects are durable over time [8]. The problem with silane is its hydrolytic instability over time, which is caused by hydrolysis due to the rupture of the Si-O bond. In addition to this, the SBU contains water and a Hydrophilic Monomer (HEMA), which may contribute to the process of hydrolysis and reduction of the bond strength over time [35]. Pereira et al., [26], observed a decreased bond strength of SBU to zirconia ceramic after 60 days of storage in water compared with Signum Zirconia Bond and Z-Prime Plus primers. According to the authors, it is possible that the water absorption of SBU adhesive resulted in decreased adhesion as a consequence of hydrolytic degradation after aging.

The present study tested the samples after $48 \mathrm{~h}$ of storage corresponding to a short-term period which did not allow the evaluation of the bond stability. It would be important to submit the samples to artificial aging methods such as long-term storage in distilled water (150 days) with additional thermal cycles $(>30,000)$ to stress the bond interface [11, $36,37]$ and to test the long-term durability of the resin-bonding to zirconia $[11,36]$. In vitro bonding testing after longterm simulation of oral conditions seems necessary before clinical recommendations can be provided [37].

\section{CONCLUSION}

Despite the limitations of this in vitro study, it can be concluded that the isolated application of silane prior to the adhesive was irrelevant in zirconia ceramic; and the Scotchbond Universal and Z-Prime Plus provided higher bond strength values to zirconia ceramic.

\section{ETHICS APPROVAL AND CONSENT TO PARTICIPATE}

This study has been approved and followed the guideline of Pontifical Catholic University of Rio Grande do Sul.

\section{HUMAN AND ANIMAL RIGHTS}

No animals/humans were used for studies that are the basis of this research.

\section{CONSENT FOR PUBLICATION}

Not applicable.

\section{CONFLICT OF INTEREST}

The authors declare no conflict of interest, financial or otherwise.

\section{ACKNOWLEDGEMENTS}

The authors thank Professor Sérgio Kato for the statistical analysis.

\section{REFERENCES}

[1] Santos MJ, Bezerra RB. Fracture resistance of maxillary premolars restored with direct and indirect adhesive techniques. J Can Dent Assoc 2005; 71: 585a-d.

[2] Bassir MM, Labibzadeh A, Mollaverdi F. The effect of amount of lost tooth structure and restorative technique on fracture resistance of endodontically treated premolars. J Conserv Dent 2013; 16(5): 413-7.

[http://dx.doi.org/10.4103/0972-0707.117494] [PMID: 24082569]

[3] Kimmich M, Stappert CF. Intraoral treatment of veneering porcelain chipping of fixed dental restorations: A review and clinical application. J Am Dent Assoc 2013; 144(1): 31-44.

[http://dx.doi.org/10.14219/jada.archive.2013.0011] [PMID: 23283924] 
[4] Sattabanasuk V, Charnchairerk P, Punsukumtana L, Burrow MF. Effects of mechanical and chemical surface treatments on the resin-glass ceramic adhesion properties. J Investig Clin Dent 2017; 8(3): e12220. [http://dx.doi.org/10.1111/jicd.12220] [PMID: 27282642]

[5] Meng X, Yoshida K, Taira Y, Kamada K, Luo X. Effect of siloxane quantity and ph of silane coupling agents and contact angle of resin bonding agent on bond durability of resin cements to machinable ceramic. J Adhes Dent 2011; 13(1): 71-8. [PMID: 21403937]

[6] Venturini AB, Prochnow C, Rambo D, Gundel A, Valandro LF. Effect of hydrofluoric acid concentration on resin adhesion to a feldspathic ceramic. J Adhes Dent 2015; 17(4): 313-20.

[PMID: 26295066]

[7] Söderholm KJ, Reetz EA. Factors affecting reliability of a resin-based cement joint. Gen Dent 1996; 44(4): $296-298,300,302$. [PMID: 8957823]

[8] Staxrud F, Dahl JE. Silanising agents promote resin-composite repair. Int Dent J 2015; 65(6): 311-5. [http://dx.doi.org/10.1111/idj.12188] [PMID: 26453196]

[9] Torres SMP, Borges GA, Spohr AM, Cury AADB, Yadav S, Platt JA. The effect of surface treatments on the micro-shear bond strength of a resin luting agent and four all-ceramic systems. Oper Dent 2009; 34(4): 399-407.

[http://dx.doi.org/10.2341/08-87] [PMID: 19678444]

[10] Anand S, Ebenezar AV, Anand N, Rajkumar K, Mahalaxmi S, Srinivasan N. Microshear bond strength evaluation of surface pretreated zirconia ceramics bonded to dentin. Eur J Dent 2015; 9(2): 224-7. [http://dx.doi.org/10.4103/1305-7456.156832] [PMID: 26038654]

[11] Kern M, Wegner SM. Bonding to zirconia ceramic: Adhesion methods and their durability. Dent Mater 1998; 14(1): 64-71. [http://dx.doi.org/10.1016/S0109-5641(98)00011-6] [PMID: 9972153]

[12] Chuang SF, Kang LL, Liu YC, et al. Effects of silane- and MDP-based primers application orders on zirconia-resin adhesion-A ToF-SIMS study. Dent Mater 2017; 33(8): 923-33. [http://dx.doi.org/10.1016/j.dental.2017.04.027] [PMID: 28606410]

[13] Zhang Y, Kelly JR. Dental ceramics for restoration and metal veneering. Dent Clin North Am 2017; 61(4): 797-819. [http://dx.doi.org/10.1016/j.cden.2017.06.005] [PMID: 28886769]

[14] Tostes BO, Guimarães RB, Noronha-Filho JD, Botelho GD, Guimarães JG, Silva EM. Characterization of conventional and high-translucency Y-TZP dental ceramics submitted to air abrasion. Braz Dent J 2017; 28(1): 97-104. [http://dx.doi.org/10.1590/0103-6440201701035] [PMID: 28301026]

[15] Atsu SS, Kilicarslan MA, Kucukesmen HC, Aka PS. Effect of zirconium-oxide ceramic surface treatments on the bond strength to adhesive resin. J Prosthet Dent 2006; 95(6): 430-6.

[http://dx.doi.org/10.1016/j.prosdent.2006.03.016] [PMID: 16765155]

[16] Wandscher VF, Fraga S, Pozzobon JL, et al. Tribochemical glass ceramic coating as a new approach for resin adhesion to zirconia. J Adhes Dent 2016; 18(5): 435-40. [PMID: 27669635]

[17] Aboushelib MN, Kleverlaan CJ, Feilzer AJ. Selective infiltration-etching technique for a strong and durable bond of resin cements to zirconiabased materials. J Prosthet Dent 2007; 98(5): 379-88.

[http://dx.doi.org/10.1016/S0022-3913(07)60123-1] [PMID: 18021827]

[18] Gamal AE, Medioni E, Rocca JP, Fornaini C, Brulat-Bouchard N. $\mathrm{CO}_{2}$ laser dentin surface treatment most effectively increased ceramic shear bond strength. Laser Ther 2018; 27(1): 48-54.

[http://dx.doi.org/10.5978/islsm.18-OR-05] [PMID: 29795971]

[19] Amaral M, Belli R, Cesar PF, Valandro LF, Petschelt A, Lohbauer U. The potential of novel primers and universal adhesives to bond to zirconia. J Dent 2014; 42(1): 90-8. [http://dx.doi.org/10.1016/j.jdent.2013.11.004] [PMID: 24246687]

[20] Tzanakakis EG, Tzoutzas IG, Koidis PT. Is there a potential for durable adhesion to zirconia restorations? A systematic review. J Prosthet Dent 2016; 115(1): 9-19.

[http://dx.doi.org/10.1016/j.prosdent.2015.09.008] [PMID: 26548872]

[21] Pilo R, Kaitsas V, Zinelis S, Eliades G. Interaction of zirconia primers with yttria-stabilized zirconia surfaces. Dent Mater 2016; 32(3): 353-62. [http://dx.doi.org/10.1016/j.dental.2015.11.031] [PMID: 26778402]

[22] Xie H, Li Q, Zhang F, et al. Comparison of resin bonding improvements to zirconia between one-bottle universal adhesives and tribochemical silica coating, which is better? Dent Mater 2016; 32(3): 403-11. [http://dx.doi.org/10.1016/j.dental.2015.12.014] [PMID: 26754430]

[23] Araújo AMM, Januário ABDN, Moura DMD, Tribst JPM, Özcan M, Souza ROA. Can the application of multi-mode adhesive be a substitute to silicatized/silanized Y-TZP ceramics? Braz Dent J 2018; 29(3): 275-81.

[http://dx.doi.org/10.1590/0103-6440201801862] [PMID: 29972454] 
[24] Perdigão J, Swift EJ Jr. Universal adhesives. J Esthet Restor Dent 2015; 27(6): 331-4. [http://dx.doi.org/10.1111/jerd.12185] [PMID: 26767920]

[25] Yoshida Y, Nagakane K, Fukuda R, et al. Comparative study on adhesive performance of functional monomers. J Dent Res 2004; 83(6): 454-8. [http://dx.doi.org/10.1177/154405910408300604] [PMID: 15153451]

[26] Pereira L de L, Campos F, Dal Piva AM, Gondim LD, Souza RO, Özcan M. Can application of universal primers alone be a substitute for airborne-particle abrasion to improve adhesion of resin cement to zirconia? J Adhes Dent 2015; 17(2): 169-74. [PMID: 25969840]

[27] Seabra B, Arantes-Oliveira S, Portugal J. Influence of multimode universal adhesives and zirconia primer application techniques on zirconia repair. J Prosthet Dent 2014; 112(2): 182-7.

[http://dx.doi.org/10.1016/j.prosdent.2013.10.008] [PMID: 24445031]

[28] Lopes GC, Spohr AM, De Souza GM. Different strategies to bond Bis-GMA-based resin cement to zirconia. J Adhes Dent 2016; 18(3): 239-46.

[PMID: 27200434]

[29] Chen L, Suh BI, Brown D, Chen X. Bonding of primed zirconia ceramics: Evidence of chemical bonding and improved bond strengths. Am J Dent 2012; 25(2): 103-8. [PMID: 22779284]

[30] Koizumi H, Nakayama D, Komine F, Blatz MB, Matsumura H. Bonding of resin-based luting cements to zirconia with and without the use of ceramic priming agents. J Adhes Dent 2012; 14(4): 385-92. [PMID: 22282752]

[31] de Souza G, Hennig D, Aggarwal A, Tam LE. The use of MDP-based materials for bonding to zirconia. J Prosthet Dent 2014; 112(4): $895-902$. [http://dx.doi.org/10.1016/j.prosdent.2014.01.016] [PMID: 24767903]

[32] Lung CYK, Matinlinna JP. Aspects of silane coupling agents and surface conditioning in dentistry: An overview. Dent Mater 2012; 28(5): 467-77. [http://dx.doi.org/10.1016/j.dental.2012.02.009] [PMID: 22425571]

[33] Magne P, Paranhos MP, Burnett LH Jr. New zirconia primer improves bond strength of resin-based cements. Dent Mater 2010 ; 26(4): 345-52. [http://dx.doi.org/10.1016/j.dental.2009.12.005] [PMID: 20047757]

[34] Maeda FA, Bello-Silva MS, de Paula Eduardo C, Miranda Junior WG, Cesar PF. Association of different primers and resin cements for adhesive bonding to zirconia ceramics. J Adhes Dent 2014; 16(3): 261-5. [PMID: 24779024]

[35] Breschi L, Mazzoni A, Ruggeri A, Cadenaro M, Di Lenarda R, De Stefano Dorigo E. Dental adhesion review: Aging and stability of the bonded interface. Dent Mater 2008; 24(1): 90-101. [http://dx.doi.org/10.1016/j.dental.2007.02.009] [PMID: 17442386]

[36] Kern M, Barloi A, Yang B. Surface conditioning influences zirconia ceramic bonding. J Dent Res 2009; 88(9): 817-22. [http://dx.doi.org/10.1177/0022034509340881] [PMID: 19767578]

[37] Kern M, Lehmann F. Influence of surface conditioning on bonding to Polyetheretherketon (PEEK). Dent Mater 2012; 28(12): 1280-3. [http://dx.doi.org/10.1016/j.dental.2012.09.010] [PMID: 23036863]

(C) 2018 Ferreira da Silva et al.

This is an open access article distributed under the terms of the Creative Commons Attribution 4.0 International Public License (CC-BY 4.0), a copy of which is available at: https://creativecommons.org/licenses/by/4.0/legalcode. This license permits unrestricted use, distribution, and reproduction in any medium, provided the original author and source are credited. 